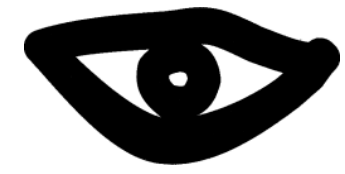

\title{
Reconstrução dos saberes docentes no ensino fundamental: abordagem transdisciplinar
}

\author{
Ortenila Sopelsa, Paulino Eidt \\ Universidade do Oeste de Santa Catarina, Brasil.
}

\begin{abstract}
RESUMO
O presente estudo foi desenvolvido mediante uma pesquisa exploratória, com o objetivo de refletir a transdisciplinaridade como atitude favorável para a reconstrução dos saberes docentes no Ensino fundamental. O estudo oportunizou a compreensão da necessidade da concepção transdisciplinar nos processos do ensino e da aprendizagem. A fim de contemplar o objetivo da pesquisa, realizamos leituras e reflexões acerca de textos de Morin (2010) com 150 alunos dos cursos de Pedagogia e Educação Física. Segundo os alunos, os estudos e as reflexões, acerca do autor possibilitaram-lhes espaços de interlocução e apropriação do conhecimento para o desenvolvimento de suas práticas pedagógicas.

Palavras-chave: Transdisciplinaridade, ensino, saberes docentes, aprendizagem.
\end{abstract}

\section{INTRODUÇÃO}

O estudo visou refletir sobre a transdisciplinaridade como atitude favorável para a reconstrução dos saberes docentes no Ensino fundamental, com o propósito de construir possibilidades para formação de um novo pensar e uma diferente vivência em educação a partir das concepções de vários autores. Uma atitude transdisciplinar contribui para superar a concepção do conhecimento científico como um saber fragmentado e reduzido a diferentes disciplinas e especialidades.

Morin (2010) pontua a necessária tomada de consciência sobre as grandes transformações do conhecimento científico e de paradigmas que provocam mudanças na forma de pensar o real. Para o autor; "o conhecimento científico está em renovação desde o começo deste século. Podemos até perguntar-nos se as grandes transformações que afetaram as ciências físicas - da microfísica à astrofísica -, as ciências biológicas da genética e da biologia molecular à etologia -, a antropologia (a perda do privilégio heliocêntrico no qual a racionalidade ocidental se via como juiz e medida de toda a cultura e civilização) não preparam uma transformação no próprio modo de pensar o real”. (MORIN, 2010, p. 27).

De maneira geral, o currículo escolar tanto quantitativo quanto qualitativamente não favorece a compreensão do conhecimento como evento relacionado, tampouco oportuniza a comunicação e o diálogo entre os saberes. Essa organização dificulta a aprendizagem significativa dos eventos da ciência e do mundo porque está alicerçada na concepção de fragmentação do conhecimento. Morin (2010, p. 16) reforça que "o desenvolvimento disciplinar das ciências não traz unicamente as vantagens da divisão do trabalho (isto é, a contribuição das partes especializadas para a coerência de um todo organizador), mas também os inconvenientes da superespecialização: enclausuramento ou fragmentação do saber.”

E imprescindível, que os professores articulem seus saberes com o conhecimento científico e a prática do cotidiano escolar e considerem, também, que o ensino e a aprendizagem são processos interligados, que o conhecimento está naturalmente ligado à vida e faz parte da existência humana.

De acordo com Santos (2008, p. 54); [...] a transdisciplinaridade maximiza a aprendizagem ao trabalhar com imagens e conceitos que mobilizam, conjuntamente, as dimensões mentais, emocionais e corporais, tecendo relações tanto horizontais como verticais do conhecimento. Ela cria situações de maior envolvimento dos alunos na concepção de significados para si.

Cabe à escola proporcionar ao aluno tanto o desenvolvimento cognitivo quanto emocional, tendo em vista que essas dimensões relacionadas é que dão significado à aprendizagem do aluno. O significado acontece quando o aluno experiecia o que está aprendendo de forma interativa e participativa no seu contexto social. Isso faz parte do trabalho colaborativo de forma transdisciplinar.

A pesquisa exploratória foi realizada a partir de estudos bibliográficos relacionados à transdisciplinaridade. Em seguida oportunizamos estudos, reflexões e socializações aos acadêmicos dos cursos de graduação em Pedagogia e Educação Física, a partir da leitura dos textos de Morin (2010), a fim de conhecer e compreender como a atitude transdisciplinar pode ser favorável para a reconstrução dos saberes docentes no Ensino Fundamental.

A socialização dos textos ocorreu durante as aulas do segundo semestre letivo de 2013. A escolha das licenciaturas se deve ao fato de os pesquisadores atuarem como professores nos cursos correspondentes. Durante as discussões e reflexos dos textos os alunos se manifestavam de forma espontânea. Cada qual procurava articular o conteúdo do texto com suas vivências no cotidiano. Ao todo, 150 acadêmicos participaram da pesquisa. Neste estudo foram selecionados $10 \%$ dos participantes, o que corresponde a 15 alunos. A escolha ocorreu por ordem de aceite dos alunos. Os dados foram registrados durante a socialização dos textos. Os alunos participantes na análise dos dados estão referenciados por números, correspondendo de 1 a 10 ao curso de Pedagogia, dos componentes curriculares Estudos Teórico-Práticos da Educação Infantil e Estudos Teórico-Práticos da 
Linguística e de 11 a 15 ao curso de Educação Física, do componente curricular Sociologia da Educação.

Vale ressaltar que o presente estudo está articulado ao projeto observatório "Estratégias e Ações Multidisciplinares nas Áreas de Conhecimentos das Ciências Humanas, Ciências da Natureza e Linguagens, na Mesorregião do Oeste Catarinense: implicações na qualidade da educação básica - Sistema Integrado Capes SICAPES/2013-216”, em desenvolvimento, no Programa de Mestrado em Educação da Unoesc.

\section{EDUCAÇÃO E COMPLEXIDADE: ALTERNATIVAS TRANSDISCIPLINARES PARA A PRÁCTICA PEDAGÓGICA}

No ensino formal, educação e prática são indissociáveis. Contudo, a articulação entre eles é complexa e, de maneira geral, tal complexidade é ignorada pelos professores. Consideramos que essa ignorância não acontece por simples descaso dos profissionais da educação, mas pela falta de estudos, reflexões e esclarecimentos, de forma individual e coletiva, na escola. Com referência a esse aspecto, a aluna 3 assim se manifesta "É a primeira vez que tenho contato com os textos de Morin. Ele tem razão quando diz que ensinamos de forma fragmentada e que a compreensão humana só vai acontecer pela experiência e por sua contextualização. Precisamos rever nossa maneira de ensinar, desde a Educação Infantil.” A aluna chama atenção para três questões pontuadas inúmeras vezes por Morin (2010): experiências, contextualização e compreensão humana. Nós, professores, precisamos ter consciência de que para contextualizar e experienciar é preciso ultrapassar as fronteiras da sala de aula, da escola. É necessário refletir como o conteúdo eleito pela escola pode contribuir na vida do aluno, na intervenção do seu contexto social e na descoberta e abertura para outras experiências. "Experiência é, portanto, experiência da finitude humana [...] O homem, experimentando, conhece os limites de toda previsão e a insegurança de todo o plano. Nele consuma-se o valor da verdade da experiência.” (GADAMER, 2008, p. 466).

A formação do professor ainda é desenvolvida de forma fragmentada. Isto é, alheia à contextualização e experiência do aluno. A aluna 4 relatou: "Morin me fez perceber que para compreender e me comunicar necessito estar aberta para conhecer o outro. Isto me fez refletir sobre minhas atitudes com as crianças. Como elas são e como eu as vejo? Por meio da minha linguagem consigo me comunicar realmente com elas?” A partir do depoimento da aluna podemos observar que ela tem consciência de que precisa avançar em alguns aspectos na sala de aula da Educação Infantil, principalmente, na questão da compreensão do outro.

$\mathrm{Na}$ grande maioria das escolas a formação continuada acontece de maneira frágil e generalizada. Não há um projeto coletivo que atenda à diversidade, tanto dos professores quanto dos alunos, que contemple diferentes disciplinas e possibilite a experimentação de professores e alunos em seu contexto social.
O modelo social contemporâneo encontra-se diante de um imenso desafio decorrente de um processo de construção do saber centrado na prática da ciência e da técnica denominada como tecnociência: delimitação dos objetos de pesquisa, especialização e fragmentação do conhecimento.

Como consequência, as práticas educativas concentraram-se na especialização e fragmentaram o currículo em disciplinas que deixaram de dialogar entre si e perderam a capacidade de reflexão com o cotidiano social dos alunos.

Nessas condições, o aluno perde o direito ao conhecimento total, interligado e reflexivo para deterse no mito do conhecimento especializado, distante das questões práticas de seu contexto social. Hoje se faz necessário pensar o conhecimento interligado com o todo e refletir sobre os processos do conhecer e suas consequências para a humanidade.

A transdisciplinaridade como conceito pedagógico introduz esta variável inovadora nos processos do ensino e da aprendizagem ao interligar, contextualizar e globalizar conhecimentos concebidos até então como individualizados e separados entre si, uma vez que [...] o conhecimento torna-se pertinente quando é capaz de situar toda a informação em seu contexto e, se possível, no conjunto global que se insere. Pode-se dizer ainda que o conhecimento progride, principalmente, não por sofisticação, formalização e abstração, mas pela capacidade de conceitualizar e globalizar. (MORIN, 2010, p. 21).

A inseparabilidade dos saberes é a atitude capaz de problematizar e contextualizar os dados e as informações, relacionando-os. Essa posição é fundamental numa sociedade de informação que separa sujeito de objeto, introduzindo uma ideologia técnicocientífica que reduz e aniquila a capacidade reflexiva dos sujeitos frente às questões sociais.

A compreensão transdisciplinar auxilia no desenvolvimento de um conhecimento pertinente, capaz de elevar os indivíduos a um estágio de pensamento reflexivo. Para tal compreensão é necessário estudo, reflexão e discussões acerca da importância das relações existentes entre as diferentes disciplinas e, entre as disciplinas e a vida do aluno, a fim de não mais persistir na contribuição da instrumentalização com base em conhecimentos fragmentários e superficiais. Nesse sentido, a aluna 2 se manifestou apontando: "Precisamos nos inteirar de todas as áreas de conhecimento, não apenas a minha gavetinha, ou seja, o Ensino de Ciências. Na contextualização do meu conteúdo, incluir a matemática, geografia, a sociologia e outros. Isso requer tempo de socialização com os colegas de trabalho". Dos comentários da aluna emerge o desejo de fazer diferente e, ao mesmo tempo, a insegurança de fazer acontecer de fato, ao menos a interdisciplinaridade, na sala de aula. De maneira geral, os professores percebem a importância disso, contudo, falta-lhes coragem para arriscar devido à sua formação, tanto acadêmica quanto continuada.

Consideramos a necessidade de as políticas públicas e os gestores das escolas voltarem interesses para a 
compreensão e contextualização do conteúdo curricular. Se há professores "acomodados" em sua gaveta de conhecimento talvez seja por falta de uma boa formação básica e contínua. A aluna 5 observou: "Considerei importante a questão de não fragmentar os conteúdos na sala de aula e sim articulá-los entre si. Acredito que isto é possível acontecer na Educação Infantil. Quero me inteirar um pouco mais sobre isso.Nunca fiz pesquisa. Talvez um projeto coletivo de ações”.

Há que se insistir na utilidade de um conhecimento que possa servir à reflexão, meditação, discussão, incorporação por todos, cada um no seu saber, na sua experiência, na sua vida. Nessa direção, a aluna 8 considera que: "É possível melhorar as aulas através da transdisciplinaridade quando for trabalhada desde o projeto pedagógico da escola, no qual, a implantação de projetos ou temas a serem trabalhados englobem todos os conhecimentos possíveis o que facilitaria o trabalho do professor."

A aluna manifesta a necessidade de que a educação transdisciplinar esteja presente no projeto pedagógico da escola. Os projetos pedagógicos, bem como os currículos educacionais, estão balizados em uma lógica reducionista do conhecimento, na melhor das hipóteses, em uma interdisciplinaridade, que não atinge o ideal de uma educação totalizante que interligue de maneira ampla todas as áreas do saber. Weil (1993, p. 16) enfatiza que "no nível do ser instalou-se uma ilusão de separação entre o sujeito e o objeto, nascendo assim um conhecimento com um processo progressivo de registro externo ao homem através de uma catalogação de dados hoje computadorizados. Nasceu a separação entre o conhecedor, conhecimento e conhecido.” Essa dissociação levou à exclusão do sujeito reflexivo e ancorou a explicação racional sobre a ciência que passa a ser fragmentada, particular e simbolicamente portadora do conhecimento verdadeiro.

Considerando que a Educação Infantil pode ser a base principal para o desenvolvimento humano procuramos orientar os alunos do Curso de Licenciatura quanto à importância de proporcionar às crianças a contextualização e a experiência na sala de aula, dando ênfase à diversidade e seu contexto. A partir das interlocuções, a aluna 1 declarou: “A educação infantil é algo muito importante, pois esta fase contribuiu no desenvolvimento da personalidade. Existe uma forte relação entre o que o autor defende. Ele enfatiza que a educação influencia constantemente na sociedade. Precisam considerar isso durante nossas ações pedagógicas”. Na reflexão da aluna pode-se perceber a importância da escola na educação formal e no desenvolvimento humano. Vale enfatizar a contribuição do planejamento coletivo, quando todos os membros da escola participam. É importante analisar o currículo eleito pela escola e avaliar como se desenvolve, relacionando ao contexto histórico-cultural em que estão inseridos todos os envolvidos. Barbosa e Horn (2008, p. 35) enfatizam: "Para haver aprendizagem, é preciso um currículo que seja significativo para as crianças e também para os professores. Um currículo não pode ser a repetição contínua de conteúdos, como uma ladainha que se repete infindavelmente no mesmo ritmo, no mesmo tom, não importando quem ouça, quem observe ou o que se aprende. Afinal, sabe-se que o conhecimento não é verdade imutável, mas algo transitório, inacabado, imperfeito e em contínua pesquisa.”

Faz-se necessário que a escola oportunize um ensino voltado Dara consciência da comblexidade humana: o respeito à diversidade. a todas as áreas de conhecimento e a compreensão aue fazemos barte de uma cultura diversa. A aluna 6 pondera que “[...] é difícil sermos compreensivos, esquecemos que quando compreendemos estamos permitindo aprender para sermos melhor, para deixar de ser ignorante, para entender qual é o sentido de uma mão amiga, de um sorriso, de dar atenção para todos, não só para aqueles que mostram que estão precisando.”

A educação transdisciplinar assegura uma interligação constante das áreas do saber, estabelecendo elementos capazes de superar o paradigma de uma educação centrada na simplificação, redução-disjunção para um paradigma da complexidade. Nessa abordagem está a superação da fragmentação do conhecimento. Isso implica "o respeito pela transcendência interior e exterior.” (NICOLESCU, 1999, p. 83).

A proposta de uma educação transdisciplinar capaz de orientar os currículos e as ações pedagógicas apresenta-se como uma alternativa não somente viável, mas fundamental para refletir as dinâmicas da sociedade. Por sua vez, a aluna 7 registra: “O texto me faz entender que o significado do outro pode não ser o meu. Entendi que as crianças também têm esta dificuldade de compreensão, nem sempre quando ensinamos algo ela associa como é de fato e acaba se confundindo".

Observa-se a necessidade de refletir sobre os processos do ensino e da aprendizagem, na sala de aula. No ato de ensinar precisamos refletir sobre algumas questões, como: a quem ensinamos? O que ensinamos? Por que ensinamos? Como ensinamos? A partir disso é possível perceber a diversidade e as singularidades que temos em sala de aula. Perceber, também, que nem sempre a linguagem é sinônimo de compreensão. Por isso, a Sociologia, a Filosofia, a Psicologia e a Pedagogia precisam ser articuladas de forma efetiva durante as atividades de ensino.

Para Morin (2010), a transdisciplinaridade aponta a necessidade de reformular os currículos e projetos pedagógicos para atender ao paradigma da educação transdisciplinar. Isso é um desafio que a Universidade deve tomar como prioridade na formação dos futuros professores. Nessa direção, a aluna 9 participa com a seguinte reflexão: “Acredito que o conhecimento não pode ser compartimentado, não são saberes distintos, mas têm ligação entre diferentes disciplinas do currículo. O conhecimento deve pautar-se em teoria e prática, onde o que é ensinado nos bancos escolares deverá ligar-se com situações concretas, para que o educando tenha um melhor entendimento do conteúdo, pois estas vivências não são divididas, mas se interliga 
a escola, sociedade e com o próprio indivíduo, de forma única e pessoal”.

É preciso assegurar a relação entre teoria e prática e a efetiva contextualização e globalização dos conteúdos escolares. Segundo Morin (2010), é primordial saber situar um conhecimento num conjunto organizado. Isso é muito mais importante no processo de aprendizagem que o desenvolvimento extremamente sofisticado de determinadas áreas e saberes que perdem ligação com as atividades práticas. No relato do aluno 10: "Na vida real não separamos os conhecimentos. Ao chegar a uma feira estudantil analisamos que a matemática não consegue estar longe da biologia ou dos demais conhecimentos. Os conhecimentos estão todos interligados.”

Cabe à educação o desafio de contextualizar os problemas sociais e perceber que a crise global está ligada ao paradigma científico de fragmentação e separação dos conhecimentos. É necessário aprendermos a complexidade para abolir qualquer tipo de cegueira que não possa refletir as consequências do progresso científico e tecnológico.

“Com a educação transdisciplinar os alunos aprenderiam a relacionar os problemas sociais com a atividade educativa, formando uma sociedade mais humana”. O relato do aluno evidencia a necessidade de uma educação que reflita a condição humana. "Isso se tornou uma questão central, visto que, por um lado a inteligência tecnológica, cega, incapaz de reconhecer o sofrimento e a felicidade humana, vem causando tantos desperdícios, ruínas e infelicidades e, de outro, a miopia alucinada do voltar-se para si mesmo". (MORIN, 2010, p. 65).

A resposta a essa questão só pode vir da necessidade urgente de um tipo de educação que possibilite entender a complexidade humana em sua forma quantitativa e qualitativa. Abandonar o egoísmo e a supervalorização de determinadas áreas para responder aos problemas humanos. Nesse contexto, a aluna 15 analisa que: "O aluno na educação transdisciplinar vai desenvolver uma visão mais ampla dos assuntos tratados em sala de aula, o que torna o conhecimento mais plausível. É preciso uma prática pedagógica que interligue os diversos conteúdos e disciplinas para fornecer significado ao aluno”.

Uma educação transdisciplinar precisa romper com o princípio de causalidade linear, o conhecimento deve ser entendido como um processo espiral de rupturas, incertezas e superações; deve estar centrada no princípio dialógico, isto é, uma educação crítica e emancipada pela força da linguagem e deve priorizar o princípio hologramático que pretende fornecer ao aluno uma visão totalizante. Esses três princípios são a base para pensarmos os fundamentos de uma prática pedagógica transdisciplinar (MORIN, 2010).

A aluna 13 pontuou: "No entanto, ainda vemos currículos estruturados que fragmentam e separam o conhecimento. A prática pedagógica dos professores está longe de atingir o ideal de uma educação problematizadora e interligada.”

A prática educacional dominante apoia-se sobre o paradigma científico de separação e fragmentação do conhecimento. Para Nicolescu (1999), a atitude transcultural, transreligiosa e transnacional pode ser aprendida. Precisamos ter claro que o ensino pressupõe muito mais aprender a religar do que aprender a separar.

Neste sentido, o aluno 11 expressa: “A transdisciplinaridade estabelece a correspondência e a integração entre o mundo interior e exterior do ser humano, superando a contradição, a dualidade e a exclusão. Que em um mundo complexo, facilita o aprendizado e agrupa as disciplinas com o autoconhecimento une o útil ao agradável, tornando-se a realidade do mundo".

O relato do aluno expressa significativamente a experiência da proposta da educação transdisciplinar a partir do texto de Edgar Morin. O aluno passa a refletir sobre a relevância do conhecimento transmitido pelos bancos escolares. Segundo Morin (2010, p. 85), “[...] um conhecimento não é pertinente porque contém uma grande quantidade de informações. Ao contrário disso, nos damos conta que, frequentemente, somos submergidos pela quantidade de informação transmitida pela televisão. As informações sobre o amanhã anulam as de hoje. Além disso, o verdadeiro problema não é o da informação quantitativa, mas o da organização da informação”. Com o aluno 12 “a transdisciplinaridade nos faz refletir sobre a realidade, afinal a vida não se resume apenas em disciplinas isoladas. A educação possibilita o entendimento do meio em que vivemos, respeitando semelhanças e diferenças e valorizando o meio ambiente. O conhecimento transdisciplinar explora a realidade, indo além do que podemos ver ou sentir."

Entendemos a partir do relato do aluno, que a Universidade possui papel destacado na formação de um novo pensamento na área educacional. Para Morin (2010, p. 21), “a reforma necessária do pensamento é aquela que gera um pensamento do contexto e do complexo. O pensamento do contexto parte da interrelação entre o fenômeno e seu contexto.” Já o pensamento complexo requer que se respeite a multidiversidade e suas várias relações. O curso de Licenciatura precisa trabalhar essa dimensão, visto que, currículos, disciplinas e grades educacionais serão pensados futuramente pelos profissionais da Educação formados pela Universidade.

A partir dos relatos dos alunos, enquanto professores e pesquisadores da universidade, sentimos a necessidade de nos aproximar mais do Ensino Básico. Enfatizamos, mais uma vez, a necessidade de a Universidade favorecer uma discussão profunda sobre as práticas pedagógicas, principalmente, nos cursos de licenciatura. É necessária a superação do paradigma do conhecimento Cartesiano e, consequentemente, efetivar um novo paradigma da educação centrado na transdisciplinaridade.

\section{CONSIDERAÇÕES FINAIS}

O estudo evidenciou que a complexidade do conhecimento exige uma nova forma de relacionar, nos contextos escolares, a teoria e a prática, para 
possibilitar aos alunos a compreensão dos contextos em que vivem e das múltiplas interdependências dos eventos das ciências, concretizados e experienciados na dinâmica da vida.

Nesse sentido, superar a fragmentação do conhecimento da visão disciplinar, da cultura da informação, é um dos desafios da educação. A proposta é uma educação transdisciplinar, que inclui a atitude de interligar as diversas áreas do saber, e que se opõe à organização curricular por especificidades, como se cada área do saber fosse independente de outros conhecimentos.

A transdisciplinaridade se concretiza numa educação contextualizada, que valoriza as experiências, que se efetiva no exercício da problematização e do trabalho coletivo, que exige do professor uma nova atitude em relação à construção do conhecimento, ao papel do aluno nos processos de ensino e de aprendizagem. Os estudos dos textos de Morin (2010) e as interlocuções com os alunos dos cursos de Licenciatura de Pedagogia e Educação Física evidenciaram que a educação precisa de currículos e ações pedagógicas que reflitam as dinâmicas da sociedade, que mudem da lógica reducionista do conhecimento para o paradigma da educação transdisciplinar.

Isso implica afirmar que é preciso abandonar as verdades absolutas e instaurar nos processos do ensino e da aprendizagem a participação efetiva do aluno, o questionamento, a associação, a reflexão e o trabalho coletivo para favorecer o desenvolvimento de consciências críticas e emancipadas frente às questões sociais, políticas, éticas, científicas e econômicas.

A escola precisa oportunizar um ensino voltado para a consciência da complexidade humana, do respeito à diversidade a todas as áreas de conhecimento, compreendendo, principalmente, que a diversidade faz parte das diferentes culturas. Nesse sentido, o professor precisa reconhecer e estar preparado científica e teoricamente, a fim de que os processos do ensino e da aprendizagem ocorram de forma efetiva.

As reflexões sobre a visão transdisciplinar como uma atitude favorável à construção dos saberes na escola apontaram ainda que Universidade precisa comprometer-se em formar profissionais da educação com compreensão holística do conhecimento e da necessidade de rever os currículos e as práticas pedagógicas. Nas interlocuções com os alunos evidenciou-se, ainda, que, regra geral, os professores percebem a necessidade de estabelecer novas formas de lidar com o conhecimento, mas lhes falta conhecimento em razão da frágil formação acadêmica. Os estudos sobre visão transdisciplinar e suas implicações no Ensino Fundamental precisam ser incluídos nos currículos de formação docente tanto no Ensino Superior quanto nos processos de formação continuada.

A presente pesquisa nos possibilitou visualizar a importância da continuação do estudo, envolvendo uma escola do Ensino Fundamental, na rede pública municipal, a fim de construir uma atitude transdisciplinar como suporte da formação docente para as práticas pedagógicas colaborativas.

\section{REFERÊNCIAS}

BARBOSA, M. C.; HORN, M. G. S. Projetualidade em diferentes tempos: na escola e na sala de aula, In: BARBOSA, M. C.; HORN, M. G. Projetos pedagógicos na educação infantil. Porto Alegre: Artmed, 2008.

GADAMER, Hans - Georg. Verdade e método: traços fundamentais de uma hermenêutica filosófica. Tradução de Flávio Paulo Meurer. 10. Ed. Petrópolis: Vozes, 2008, v. 1

MORIN, E. Ciência com consciência (13. ed.). Rio de Janeiro: Bertrand Brasil Ltda, 2010.

NICOLESCU, B. $O$ Manifesto $d a$ Transdisciplinaridade. Tradução Lúcia Pereira de Souza. São Paulo: Trion, 1999.

SANTOS, A. Complexidade e Transdisciplinaridade em Educação: cinco princípios para resgatar o elo perdido. Rev. Educ., Rio de Janeiro, v. 13, n. 37, jan./ abr. 2008.

WEIL, P.; D’AMBROSIO, U.; CREMA, R. A. Rumo à Nova Transdisciplinaridade: sistemas abertos de conhecimento. São Paulo: Sumus, 1993. 